\title{
EP625
}

\section{Four cases of hyperparathyroidism-jaw tumor syndrome in young patients with primary hyperparathyroidism in Russia}

\section{E. Mamedova, N. Mokrysheva, E. Pigarova, I. Voronkova, E. Vasilyev, V. Petrov, L. Rozhinskaya, A. Tiulpakov}

\author{
Endocrinology Research Center, Moscow, Russia
}

- Introduction: Hyperparathyroidism-jaw tumor (HPT-JT) syndrome is a rare autosomal-dominant disorder caused by mutations in CDC73 tumor suppressor gene. To date about 80 mutations in CDC73 have been described. Four patients among a cohort of young patients (<40 y.0.) with primary hyperparathyroidism (PHPT) underwent next-generation sequencing (NGS) (Ion Torrent ${ }^{\mathrm{TM}}$ PGM $^{\text {TM }}$, Thermo Fisher Scientific-Life Technologies, USA) using a custom-designed lon AmpliSeq ${ }^{\text {TM }}$ gene panel.

- Case 1. A female with PHPT manifestation at age 20, osteitis fibrosa cystica (OFC), kidney microlithiasis, serum Ca $4.09 \mathrm{mmol} / \mathrm{l}$ (2.15-2.55), parathyroid hormone (PTH) $2440 \mathrm{pg} / \mathrm{ml}$ (15-65) due to parathyroid carcinoma, and endometrial polyp at diagnosis. At age 26 her PHPT recurred as lung metastases of parathyroid carcinoma, requiring surgical intervention. NGS revealed a novel nonsense mutation in exon 3 p.R91X.

- Case 2. A female with PHPT manifestation at age 24, severe OFC, kidney microlithiasis, serum Ca 3.36 $\mathrm{mmol} / \mathrm{l}, \mathrm{Ca}^{2+} 1.56 \mathrm{mmol} / \mathrm{l}$ (1.03-1.29), PTH 558.8 $\mathrm{pg} / \mathrm{ml}$ due to parathyroid carcinoma. A patient had positive family history, with polycystic kidney disease in her mother. NGS revealed a nonsense mutation in exon 6 P.Q166X.
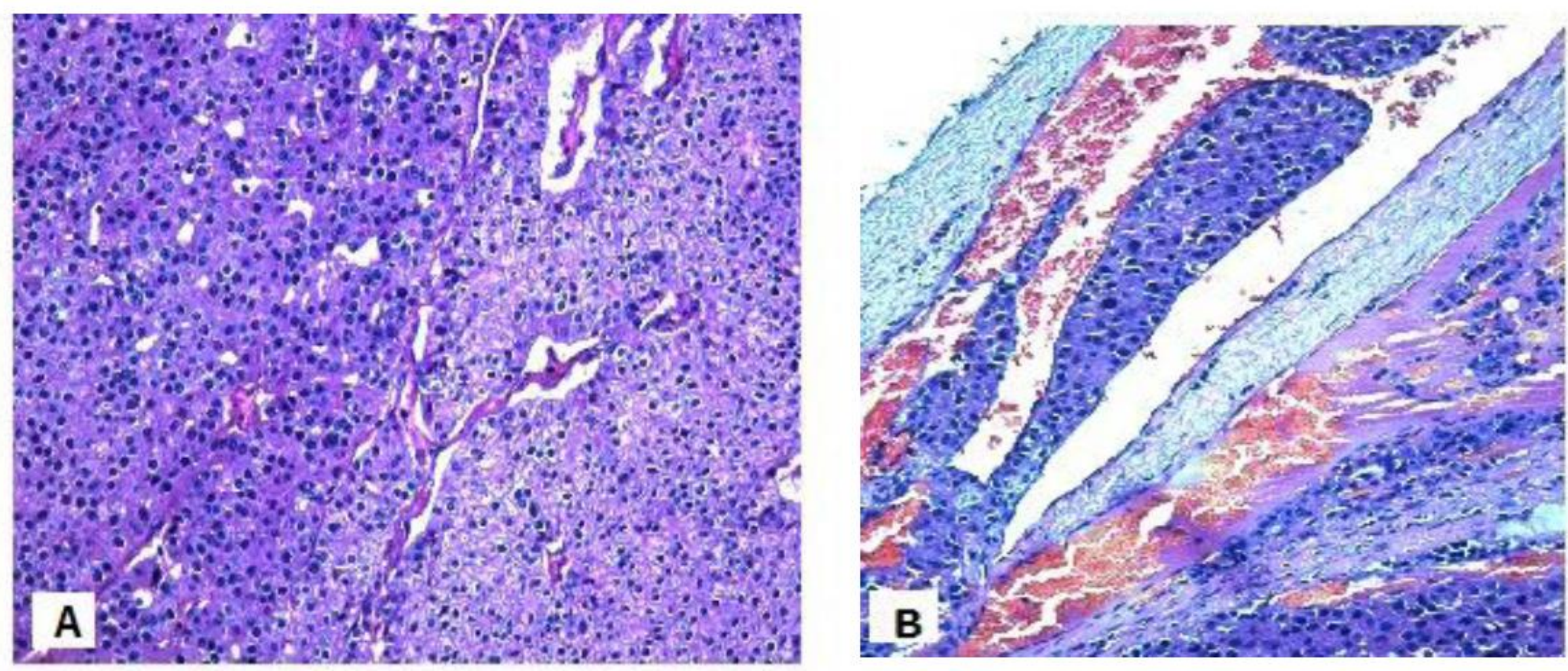

A - two types of chief cells, H\&Ex200;

$B$ - Vascular invasion, H\&Ex400
- Case 3. A male with PHPT manifestation at age 22, severe OFC, serum Ca $3.9 \mathrm{mmol} / \mathrm{l}, \mathrm{Ca}^{2+} 1.84 \mathrm{mmol} / \mathrm{l}$, PTH $1441 \mathrm{pg} / \mathrm{ml}$ due to parathyroid carcinoma. NGS revealed a novel nonsense mutation in exon 7 p.R229X.

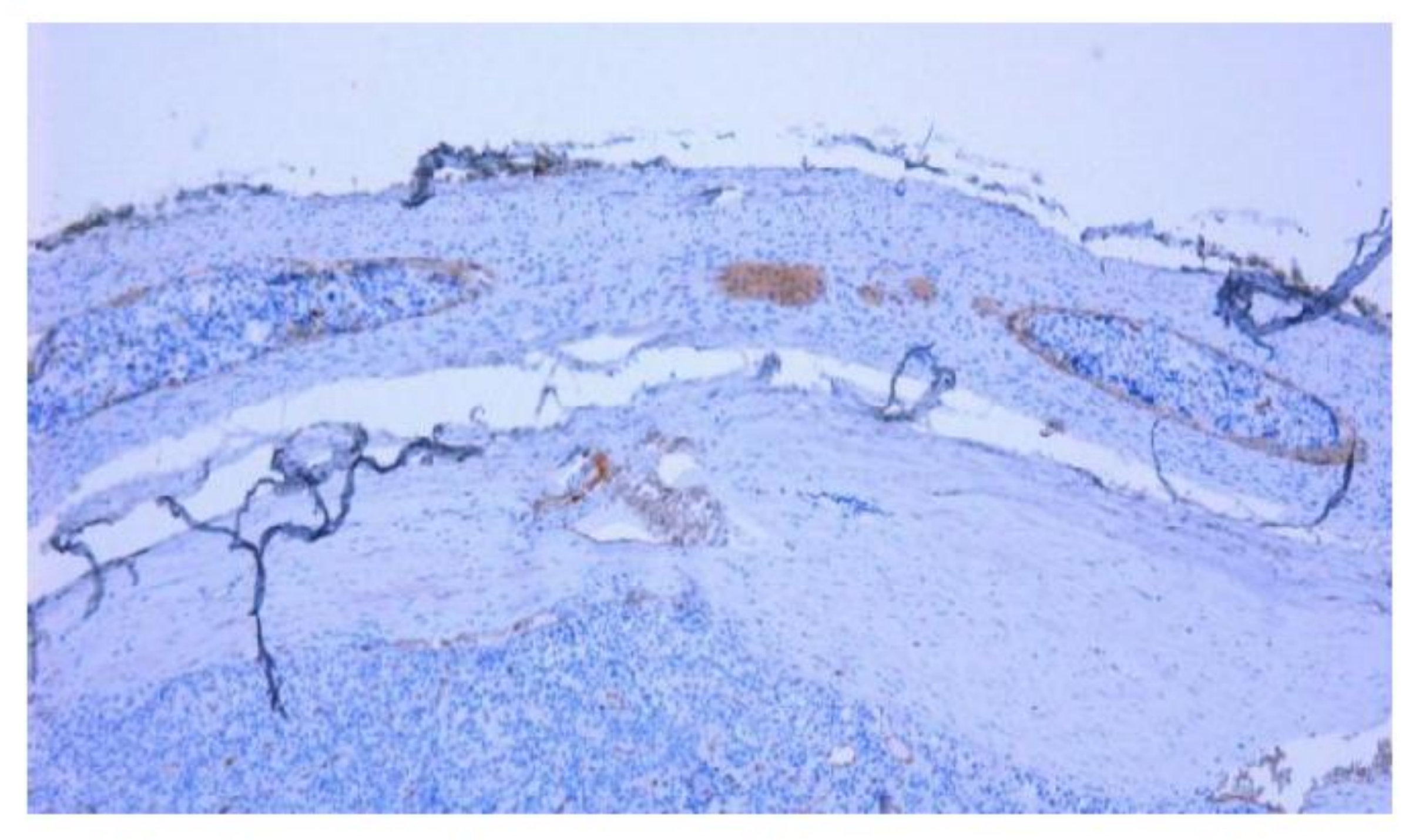

Vascular invasion, anti-CD31 antibodyx50

- Case 4. A female with mild PHPT manifestation at age 30 , serum Ca $2.94 \mathrm{mmol} / \mathrm{l}, \mathrm{Ca}^{2+} 1.24 \mathrm{mmol} / \mathrm{l}$, PTH $125.1 \mathrm{pg} / \mathrm{ml}$ due to single parathyroid hyperplasia. NGS revealed a novel missense mutation in exon 8 p.R263C.

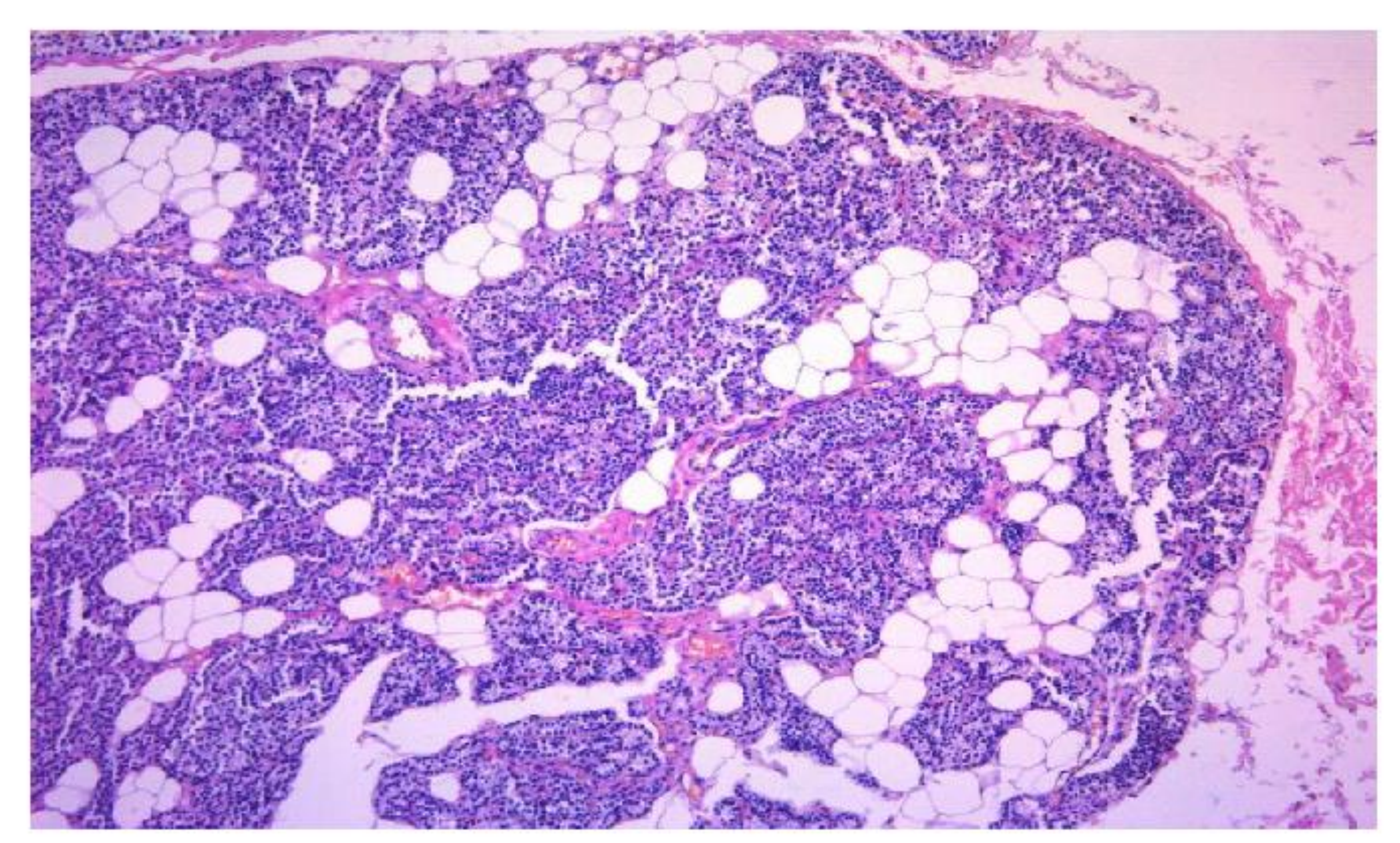

Parathyroid hyperplasia, H\&Ex100

Conclusion: We describe four cases of HPT-JT syndrome in young patients with PHPT in Russia. 3 of 4 mutations are described for the first time. Occurrence of nonsense CDC73 mutations in patients with parathyroid carcinoma and a missense mutation in a patient with parathyroid hyperplasia may reflect various degrees of parafibromin dysfunction.

The reported study was funded by RFBR according to the research project (grant) № 16-34-00401 Mo^_a. 